Original article

\title{
T-Helper 4 and Cytotoxic T-Lymphocites, Interleukin- 4 and 10 in HIV-Seropositive Patients with Uncomplicated Plasmodium Falciparum Malaria.
}

\author{
Mirabeau Y Tatfeng ${ }^{1 *}$, Dennis E Agbonlanor ${ }^{2}$ and Marie A Abouo ${ }^{3}$ \\ Received 18 June, 2010 Accepted 3 November, 2010 Published online 21 December, 2010
}

\begin{abstract}
:
Background and Aim: The biological functions of anti-inflammatory cytokines appear to be crucial in the immune response. The aim of this study is to determine the levels of the anti-inflammatory (IL-4 and IL-10) cytokine response in malaria HIV and HIV-malaria coinfected individuals with uncomplicated Plasmodium falciparum malaria. Methods: Levels of IL-4 and IL-10 of 111 malaria-infected, 97 HIV-malaria co-infected and 79 HIV seropositive subjects as well as 73 controls were determined by enzyme linked immunosorbent assay. CD4 and CD8 cells were counted using the Dynabeads T4-T8 quantification protocol while haematological parameters were estimated using standard haematological techniques. Results: IL-4 and IL-10 levels were significantly higher in malaria patients $(8.18 \pm 6.41 \mathrm{pg} / \mathrm{ml}$ and $26.29 \pm 12.08 \mathrm{pg} / \mathrm{ml})$ than in HIV $(5.208 \pm 1.69 \mathrm{pg} / \mathrm{ml})$ or HIV-malaria $(4.415 \pm 3.23 \mathrm{pg}$

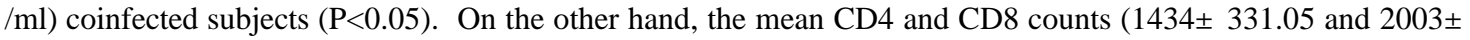
405.73 cells $/ \mu$ l respectively) of malaria infected individuals were significantly elevated $(\mathrm{P}<0.05)$ as compared to HIV, HIV-malaria and control groups. Conclusion: The results of this study suggest that malaria antigen may initiate a higher anti-inflammatory cytokine response than HIV or HIV associated with malaria.
\end{abstract}

Key words: anti-inflammatory cytokines, HIV, Malaria, Nigeria

\section{INTRODUCTION}

Malaria and human immunodeficiency virus (HIV) are among the most common infections in sub-Saharan Africa and, to a lesser extent, in other developing countries. It is estimated that 38 million Africans are infected with HIV-1, whereas 300 million to 500 million suffer from malaria each year [1]. Therefore, any interaction between these infections will have a significant impact on public health, even if the statistical effect is modest. On a population basis, an increased prevalence of malaria and increased parasite density in HIV-infected individuals could lead to increased malaria transmission and affect both HIV-positive and HIV-negative individuals [1]. The increased risk of clinical malaria in HIV-positive subjects could increase the burden on clinical services in areas where HIV-1 is prevalent.

Infection with HIV-1 causes progressive cellular immunosuppression, and any resulting impairment in the im- mune response to malaria might be associated with failure to prevent infection or to suppress parasitemia and clinical disease [2]. Both the cellular and humoral arms of the adaptive immune system are pivotal elements in the eradication of Plasmodium from the body, and both are critically dependent on CD4+ lymphocytes [3]. It has been firmly established that $\mathrm{CD} 4+\mathrm{T}$ cells are comprised of at least two functionally different subsets, distinguished on the basis of lymphokine secretion in Th1 (IFN- -producing) and Th2 (interleukin-4 producing) cells. Of particular interest is the fact that CD4+ T cells, of either Th1 or Th2 type, also have regulatory functions in human $P$. falciparum malaria. Both Th1 and Th2 responses seemto be required to control the infection, but they need to be adequately tuned in intensity and time $[4,5]$. Thus, both Th1 and Th2 are activated during infection with $P$. yoelii $17 \mathrm{XL}$ in C57BL/6 mice, but early activation of Th2 cells is deleterious, conferring susceptibility to infection [6]. In addition, in $P$. chabaudi infection there is a shift from Th1 to Th2 during peak para-

\footnotetext{
${ }^{1}$ Department of Medical Laboratory Science, College of Health Sciences, Niger Delta University, Wilberforce Island, Bayelsa state.

${ }^{2}$ Biotechnology Unit, Lahor Research Laboratories and Medical Centre, Benin City

${ }^{3}$ Department of Medical Laboratory Science, Madonna University, Elele, Rivers State

*Corresponding Author:

Department of Medical Laboratory Science, Niger Delta University

E-mail: youtchou@yahoo.com
} 
sitemia that is important for clearance of parasites [7]. In contrast, the effectiveness of CD8+ T cells against the asexual blood stage of Plasmodium appears to be limited, although CD8+ T lymphocytes might contribute to the fight against the parasite through secretion of cytokines as IFN- $\gamma$, IL-4 IL-10 etc. The effects of HIV on malaria in adults are now well documented. The true clinical impact of malaria on HIV progression remains to be determined [8]. However, the magnitude and clinical significance of these potential interactions need further research [9].

In this study we determine the strength of the antiinflammatory cytokines (IL-4 and IL-10) response in malaria, HIV and HIV- malaria coinfected individuals.

\section{MATERIALS AND METHODS}

\section{Study Design}

A total of 287 individuals enrolled for this study presented with symptoms of uncomplicated malaria (i.e. temperature ranging from $37-40^{\circ} \mathrm{C}$, joint pains, no nervous system involvement) between the months of January and June 2006 at medical centers in the Benin metropolis (Lahor Medical Centre, Suyi Hospital and Milestone Hospital). The distribution of study subjects was as follows: 111 malaria infected, 97 HIV-malaria co-infected and 79 HIVseropositive subjects as well as 73 controls. Benin City is ocated in the southern region of Nigeria where malaria and HIV infections are endemic. All the participants were tested for HIV and malaria and were grouped accordingly. Written consent from the patients was sought before blood samples were collected for analysis. Patients who had started antimalarials or antiretroviral therapy and those with intestinal infections were excluded from this study.

\section{Cytokine assay}

IL-4 and IL-10 cytokines levels were assayed using enzyme linked immunosorbent assay (ELISA or EIA) [10] (MABTECH Inc. Company, Sweden).

\section{CD4/CD8 Count}

The CD4 and CD8 counts were estimated using Dynabeads T4-T8 Quantification Protocol (Dynal Biotech ASA, Oslo, Norway) following the manufacturer's instructions as follows.

\section{Pack contents:}

- 2ml of Dynabeads CD14 monoclonal antibodies

- $2 \mathrm{ml}$ of Dynabeads CD4 monoclonal antibodies

- $2 \mathrm{ml}$ of Dynabeads CD8 monoclonal antibodies

- Phosphate buffer saline

- Eppendor microfuge

Sample Preparation EDTA or ACD whole blood was mixed for 2 minutes at room temperature, and $225 \mu 1$ and $225 \mu 1$ of washing/diluent buffer $250 \mu \mathrm{l}$ and whole blood, respectively, were added to $1 \mathrm{ml}$ microfuge tubes.

\section{Monocyte Depletion}

After addition of $25 \mu 1$ of Dynabeads CD14, the tube was capped and mixed carefully by inversion, and the mixture was incubated with a tilting and rotation action for 10 minutes at room temperature. Each tube was placed in a Dynal MPC-S magnet for 2 minutes. $200 \mu 1$ of monocytedepleted blood was carefully transferred to 2 sets of tubes, and the tubes containing the rosette monocytes were safely discarded.

\section{T4-T8 lymphocyte isolation}

$200 \mu$ l of washing buffer was added to each of the 2 tubes containing $200 \mu \mathrm{l}$ of monocyte depleted blood, followed by $25 \mu 1$ of Dynabeads CD4 to one of the tubes and $25 \mu 1$ of Dynabeads CD8 to the other. The tubes were capped and the content mixed carefully by inversion. Incubation with a tilting and rotating action was done for 10 minutes at room temperature. The tubes were placed in the Dynal MPC-S for 2 minutes, and the supernatant was discarded without removing the tubes from the MPC-S magnet. The isolated cells were washed by adding 500 $\mu$ l of buffer/ diluent to each tube, and the tubes were removed from the MPC-S magnet. A precut sheet of paraffin was placed over the tubes. The rosettes were resuspended by inverting the tubes a few times. The paraffin sheet was safely discarded and refitted in the MPC-S magnet for 2 minutes before the supernatant was discarded. The washing steps were repeated once.

\section{T4 and T8 cell counting}

The cells were resuspended in $100 \mu$ l of $2 \%$ glacial acetic acid tainted with gentian violet and fixed properly. The Neubaeur Counting Chamber was charged and the rosettes were counted immediately in one counting area of 1 $\mathrm{mm}$ by $1 \mathrm{~mm}$ with a depth of $0.1 \mathrm{~mm}$

\section{Calculation}

A dilution factor of 1/2 was applied because the isolated cells from $250 \mu 1$ of whole blood were resuspended in $225 \mu 1$ of buffer $+25 \mu 1$ of Dynabeads CD14.

The volume of suspension in a counting area was equal to $1 \mathrm{mmX} 1 \mathrm{mmX} 0.1 \mathrm{~mm}=0.1 \mathrm{~mm}^{3}$. If $X$ rosettes are counted in the counting area of $0.1 \mathrm{~mm}^{3}, \mathrm{~T} 4$ or $\mathrm{T} 8=2 \mathrm{X} 10 \mathrm{Xcells} / \mu \mathrm{l}$ will be counted in $1 \mathrm{~mm}^{3}$.

\section{Haematological parameters}

The haematological parameters of the subjects (differential white blood cells and total white blood cells) were assessed using the Swelab Automatic Counter (Boule Medical Stockholm, (Sweden).

\section{Statistical analysis}

Data obtained from this study were analyzed using 
Table 1: Mean comparison of IL-4, IL-10 and haematological indices of HIV, malaria and HIV-malaria coinfected subjects.

\begin{tabular}{lllll}
\hline Cytokines & Malaria & HAR-M & HIV & CONTROL \\
& $\overline{\mathrm{x}} \pm$ S.D & $\overline{\mathrm{x}} \pm$ S.D & $\overline{\mathrm{x}} \pm$ S.D & $\overline{\mathrm{x}} \pm$ S.D \\
$\mathrm{IL}-4(\mathrm{pg} / \mathrm{ml})$ & $8.18 \pm 6.41$ & $4.415 \pm 3.23$ & $5.208 \pm 1.69$ & $5.846 \pm 1.819$ \\
$\mathrm{IL}-10(\mathrm{pg} / \mathrm{ml})$ & $26.29 \pm 12.08$ & $4.33 \pm 10.39$ & $6.86 \pm 10.98$ & $26.008 \pm 13.23$ \\
$\mathrm{CD} 4(\mathrm{cells} / \mu \mathrm{l})$ & $1434 \pm 331.05$ & $207.0 \pm 841.09$ & $274 \pm 465.08$ & $1314 \pm 207.03$ \\
$\mathrm{CD} 8(\mathrm{cells} / \mu \mathrm{l})$ & $2003 \pm 405.73$ & $275 \pm 20.45$ & $317 \pm 11.00$ & $1073 \pm 119.13$ \\
\hline
\end{tabular}

Key: HIV-M: Malaria HIV co- infection

\section{ANOVA}

\section{RESULTS}

The mean IL-4 concentration was significantly higher in malaria patients $(8.18 \pm 6.41 \mathrm{pg} / \mathrm{ml})$ than the levels obtained in HIV $(5.208 \pm 1.69 \mathrm{pg} / \mathrm{ml})$ and HIV-malaria (4.415 $\pm 3.23 \mathrm{pg} / \mathrm{ml})$ coinfected subjects $(\mathrm{P}<0.05)$. Furthermore, mean IL-10 concetration in malaria patients $(26.29 \pm 12.08$ $\mathrm{pg} / \mathrm{ml}$ ) was significantly higher than the levels obtained in HIV $(6.86 \pm 10.98 \mathrm{pg} / \mathrm{ml})$ and malaria-HIV $(4.33 \pm 10.39 \mathrm{pg} /$ $\mathrm{ml})$ coinfected subjects $(\mathrm{P}<0.05)$. The mean haematological parameters revealed a significant difference in the CD4 count $(1434 \pm 331.05$ cells $/ \mu$ l) of malaria-infected individuals when compared to values obtained in HIV (274 465.0 cells $/ \mu \mathrm{l})$ and HIV-malaria $(207.0 \pm 841.09$ cells $/ \mu \mathrm{l})$ coinfected subjects respectively $(\mathrm{P}<0.05)$. The CD8 count was significantly higher in malaria-infected subjects (2003 \pm 405.73 cells $/ \mu \mathrm{l})$ than in controls, HIV $(317 \pm 11.00 \mathrm{cells} / \mu \mathrm{l})$ and HIV-malaria coinfected $(275 \pm 20.5$ cells $/ \mu \mathrm{l})$ subjects (P $<0.05$ ), while packed cell volume was significantly higher in malaria, HIV and HIV- malaria coinfected individuals than in control subjects (Table1).

\section{DISCUSSION AND CONCLUSION}

The depletion in haematological cells may be associated with lowered serum levels of immunological mediators, a direct outcome of which could be the poor immune response observed in HIV-infected individuals [11]. This study revealed that the mean IL- 4 and IL-10 concentrations were significantly higher in malaria patients than those obtained in HIV and HIV-malaria coinfected subjects $(\mathrm{P}<0.05)$. Although Torre et al [12] reported that IL- 4 and IL-10 did not seem to be involved during the acute phase of malaria, Wrinkler et al [13] observed a more pronounced Th2driven immune response during the acute phase of untreated and uncomplicated malaria caused by P. falciparum, with a shift towards Th1 responsiveness induced by parasite clearance. The lowered levels of Th2 obtained in HIV and HIVmalaria coinfected individuals could be associated with the depletion of CD4 and other cells in these group of subjects. On the other hand, there was no significant 'ibferabce shen the levels in control subjects was compared to values obtained in HIV and malaria-HIV coinfected subjects (P> 0.05). Several members of the cytokine network have been found to play an important role in controlling the replication of the human immunodeficiency virus (HIV) in several experimental systems. Their effects can be categorized in the following three functional groups: (1) HIV-inductive cytokines; (2) HIV-suppressive cytokines; (3) cytokines with both activating and inhibiting capacities. Studies on the mechanism of these molecules have highlighted the fact that several steps of the retrovirus life cycle, from binding to budding of progeny virions from the infected cell, are affected by cytokines. This general concept has been recently substantiated by the discovery that certain beta-chemokines can act as blockers of viral entry by interfering with HIV co -receptors [14].

In conclusion, this study revealed that $P$. falciparum infection seems to initiate a stronger IL-4 and IL-10 response than HIV or HIV associated with malaria. However, more cohort studies are required to assess the impact of malaria infection on other anti-inflammatory cytokines as well as pro-inflammatory cytokines.

\section{REFERENCES}

1 . Whitworth J, Morgan D, Quigley M, Smith A, Mayanja B, Eotu H, Omoding N, Okongo M, Malamba S, Ojwiya A. Effect of HIV-1 and increasing immunosuppression on malaria parasitaemia and clinical episodes in adults in rural Uganda: a cohort study. Lancet 2000; 356: 1051-6.

2 . Good MF, Doolan DL. Immune effector mechanisms in malaria. Curr Opin Immunol 1999; 11: 412-9

3 . Dong C, Flavell RA. Th1 and Th2 cells. Curr. Opin. Hematol. 2001; 8: 47-51.

4 . Torre D, Speranza F, Giola M, Matteelli A, Tambini R, Biondi G. Role of Th1 and Th2 cytokines in immune response to uncomplicated Plasmodium falciparum malaria. Clin. Diagn. Lab. Immunol. 2002; 9: 348-351.

5 . Troye-Blomberg M, Berzins K, Perlmann P. T-cell control of immunity to the asexual blood stages of the malaria 
parasite. Crit. Rev. Immunol. 1994; 4: 131-155.

6 . Kobayashi F, Morii T, Matsui T, Fujino T, Watanabe Y, Weidanz WP, Tsuji M. Production of interleukin 10 during malaria caused by lethal and nonlethal variants of Plasmodium yoelii yoelii. Parasitol. Res. 1996; 82: 385-391.

7 . Helmby H, Kullberg M, Troye-Blomberg M. Expansion of IL-3-responsive IL-4-producing non-B non-T cells correlates with anemia and IL-3 production in mice infected with blood-stage Plasmodium chabaudi malaria. Eur. J. Immunol. 1998; 28: 2559-2570.

8 . Whitworth JA, Hewitt KA. Effect of malaria on HIV-1 progression and transmission. Lancet 2005; 365: 196-7.

9 . Khoo S, Back D, Winstonley P. The potential for interactions between antimalarial and antiretroviral drugs. Aids 2005; 1995-1005.

10 . Baron EJ, Peterson LR, and Finegold FS. Immunodiagnosis In: Bailey and Scott Diagnostic Microbioly, $9^{\text {th }}$ Edtion. Editors: James F.S., Lisa M.Potts, Chris M., and Julie T. Publisher, Mosby. 1994: 134-145.

11. Tatfeng YM, Agbonlahor DE. Proinflammatory cytokines and haematological indices in HIV seropositive adults with uncomplicated Plasmodium falciparum malaria. JTMH. 2008; 36(2): 73-75.

12. Torre D, Giola M, Speranza F, Matteelli A, Basilico C. Biondi G. Serum levels of interleukin-18 in patients with uncomplicated Plasmodium falciparum malaria. Eur. Cytokine Netw. 2001; 12: 361-364.

13. Winkler S, Willheim M, Baier K. et al. Reciprocal regulation of Th1- and Th2-cytokine-producing T-cells during clearance of parasitemia in Plasmodium falciparum malaria. Infect. Immun. 1998; 66: 6040-6044.

14. Vicenzi E, Biswas P, Mengozzi M Poli G. Role of proinflammatory cytokines and beta-chemokines in controlling HIV replication. J. Leukocyte Biol. V 1997; 62(1): 34-40. 